\title{
Reply
}

\section{A Response to McMurtry's System of Fallacy in the Media}

\author{
WALTER ULRICH University of Northern lowa
}

Key Words: Agenda setting, mass media, fallacy, capitalism, bias, social structure, evidence, censorship.

Abstract: In the Fall 1988 issue of Informal Logic, John McMurtry suggests that the current mass communication system "obstructs and deforms our thinking and our reasoning by a general system of deception" (p. 133). This essay suggests that McMurtry's view of the mass media is inaccurate. The mass media needs to make choices about what material it includes; McMurtry"s description of the media could be explained by a rational theory of media agenda setting. Finally, it is argued that critical thinkers need to go beyond the mass media to make decisions; the mass media should not be expected to provide all arguments and viewpoints.

In the Fall 1988 issue of Informal Logic, John McMurtry raises a potentially serious attack on the structure of reasoning in our society. ${ }^{1} \mathrm{He}$ suggests that the structure of the current mass communication system "obstructs and deforms our thinking and our reasoning by a general system of deception" (p. 133). He develops this position by advancing four general principles which he suggests guide and restrict public discussion:

Principle I: There is a basic social-structural fact (B.S.S.F.). Its defining principle, applicable to most or all existing social orders, is that large capitalist corporations or a state party control production and distribution of social goods so as to maximize private capital or social command owned by these capitalist corporations or state party. (p. 134)

Principle II: Corresponding to the basic social-structural fact as defined by Principle I is a range of possibility of what can be said in the mass media of the society in question. This range of possibility is defined, in turn, as whatever does not contradict the necessity or value of this basic social-structural fact. (p. 136)

Principle III: Exclusion of a statement or a set of statements from the range of what can be said in the public realm occurs in proportion to its contradiction to acceptance of the basic social-structural fact as necessary and good, (p, 140)

Principle IV: What validates the basic socialstructural fact as necessary or moral, and invalidates opposition to it as impractical or immoral, qualifies for selection for mass media production. (p. 142)

To support principle II, he lists thirty "examples of the unspeakable in the mass media of the English-speaking world" (pp. 137-138). These are claims that theoretically cannot be advanced in the mass media in our society.

McMurtry raises a number of important issues concerning the nature of mass media in our society and the implications of mass media on critical thinking. There are two major issues raised by McMurtry that need to be addressed. First, is his description of the current system of mass media in English-speaking countries accurate? Second, if his description is accurate, would such a mass media system be undesirable? This essay will address these two issues.

\section{The "Speakable" Unspeakable}

McMurtry argues that the current mass media does not present "arguments, posi- 
tions or facts that contradict the necessity or value" of the B.S.S.F. (p. 136)..$^{2}$ This argument is troublesome for a number of reasons. First, it is made with almost no support; ${ }^{3}$ there is no systematic survey of the mass media's coverage cited to support his criticism of the mass media. For example, his discussion of principle IV contains not a single reference to any study of how the mass media, in fact, covers issues.

Second, McMurtry is overly simplistic in his description of our social structure. For example, why we should accept his formulation of the "basic social-structural fact (B.S.S.F.)" is unclear. McMurtry focuses on the control of the ownership of the means of production, while others may argue that the B.S.S.F. is best described by defining our society as maledominated, white-dominated, democratic, technologically based, class-dominated, or even dominated by a Judeo-Christian heritage. Why we should focus on one B.S.S.F. instead of the others is unclear. In addition, the formulation of a society's B.S.S.F.'s may be contradictory; promoting one B.S.S.F. may involve an attack on the others. $^{4}$

In addition, to label the American system capitalist oversimplifies the American economy; it is a mixed economy. Some aspects of the American economy-the welfare system, some segments of medicine and agriculture, and the postal service, for example, are more socialist than capitalist. Even the capitalist sectors are highly regulated: political speech by corporations is regulated; environmental and safety restrictions are frequently imposed.

These restrictions are proposed in the mass media, debated in the mass media, and reported in the mass media. The mass media discusses proposals to restrict PACs (political action committees). The mass media has frequently criticized the influence of lobbies on Congress, and environmental issues have been heavily debated. Virtually no aspect of the American economy is not debated from tax reform (which according to McMurtry is an "unspeakable") to environmental regulations, to military spending. Even if criticisms of capitalism, in general, are not debated in the mass media, whether state regulations are justified in specific sectors of the economy is frequently discussed.

A recent editorial in the Progressive, citing Michael Klare (neither source is pro-capitalist) suggests:

As Klare suggests, we have all suffered the
effects of the Cold War. One casualty has
been our ability to allow more than two cat-
egories of thought-good/bad, East/West,
socialism/capitalism--the sort of bipolar
assessment that semanticists call "two val-
ued orientation." The ending of the Cold
War should liberate our mind to see the world
more clearly, in all of its complexity.

The American society is much more complex than McMurtry implies; its nature is constantly being refined, new laws that restrict and regulate industry are constantly being proposed and debated. To view the world as static and two sided distorts the dynamic, changing shape of our society.

Third, for many of his examples, he is simply incorrect in his description of the mass media. I agree that the mass media does not print every negative statement about the B.S.S.F. On the other hand, the mass media does print a great deal of information that undermines the assumptions of the B.S.S.F. Newspapers criticize high taxes, and print complaints of taxes and profits in their business section. The cover story of Business Week's May 6, 1991 issue, for example, was "Are CEO's Paid Too Much?" Exxon and other companies have been criticized for environmental reasons, and Earth Day received massive publicity in every major publication-in fact, the editors of Time have gone so far as to say they will take an advocacy role in coverage of environmental issues (disproving his "unspeakable" \#18: "Pollution/poverty are specially advantageous to the major shareholders of private enterprise."). In fact, the mass media tends to present only 
the environmental side of ecological issues. ${ }^{6}$ The mass media's coverage of Donald Trump and Leona Helmsley hardly suggests that the press does not question the assumption that wealth is correlated with merit (\#14: "There is no correlation between people's wealth and their merit." and \#16: "The very rich ought not to be admired, but rather condemned for their acquisitive self-interest at others' expense.") -a conclusion further supported by reading any issue of the National Enquirer or Star. McMurtry's claim that one "unspeakable" statement is that "there may be better alternatives for long-term sexual union than the private property structure of stateregulated marriage" (\#21) can be disproved by watching an afternoon of soap operas or an evening of network TV. The acid rain controversy and other threats to Canada from the United States have also received publicity ("unspeakable" \#13: "The greatest danger to Canada's freedom and security comes from the United States.").

Even during a popular war such as the Kuwait crisis in the United States there were nightly reports on the anti-war movement far out of proportion to the actual support for such a position. ${ }^{7}$ Several articles argued that we intervened in the Middle East to assist big business in keeping the price of oil low and to reduce pressure to decrease oil consumption. ${ }^{8}$ The coverage of the civil rights and women's rights movement and the success of the movie "Dances with Wolves" undermine his claim that statement \#12 ("The history of Western civilization is largely a history of genocide against non-white peoples and cultures.") and \#21 (there are alternatives to marriage) are "unspeakables." Unspeakable \#29 "Christianity calls for the redistribution of wealth") is undermined by Pope John Paul II's "Centesimus Annus."

For other issues, he assumes the public is ignorant. Election results are widely publicized (and complaints of low voter turnout are commonplace); any person with an elementary knowledge of math could calculate that $70 \%$ of the population did not vote for Reagan (unspeakable \#8), although why this statement is worth printing is unclear (just because voters did not vote does not mean they would have voted against Reagan). Workers need only to look at their paychecks to discover unspeakable \#24 ("Over 90\% of Canadian citizens are not capitalists but members of the working class who depend for their living on wages or salaries."). ${ }^{10}$ They can form their own judgement on "unspeakable" \#2 ("The capitalist workplace is anti-democratic.") without help from the mass media. Does McMurtry really think most people believe that corporations do not make a profit from selling weapons (\#9: "The arms race and international wars are very profitable for most multinational corporations"), a conclusion much discussed in the mass media in the first quarter of 1991 ? Why the mass media needs to tell people what they already know is unclear, at best.

Individuals are not denied the "effective right to criticize the capitalist system" (\#11). They have an unlimited right to speak out against the system. Unions have legal protection to organize, picket, and to publicize their views; these activities are often covered in the mass media. If $\mathrm{Mc}$ Murtry's argument is that those opposed to capitalism do not have the right to force mass media to say what they think it should say, I doubt that many people would deny that, but it is also a trivial attack. The argument that people are punished in any way for speaking out against the social structure is developed only in a footnote (p. 148), and there is no evidence that anyone in the United States has been punished for expressing an idea. The history of first amendment litigation would suggest that where individuals have been prevented from expressing an idea, the restrictions have been successfully challenged.

McMurtry would probably respond that tolerance for small amounts of dissent is merely symbolic, creating an atmosphere of tolerance to hide the more sinister 
"censorship" of critical views:

... such variation in what can and cannot be supposed, inferred and argued does not mitigate the hold of this underlying structure of unreason, but only masks it in the play of diversity. This play of diversity is essential to the appearance of "pluralism" in a society when its communication field is in fact systematically intolerant of basic alternatives or criticisms. (p. 141)

This defense, however, removes his thesis from an arena where it can be rationally evaluated and makes his thesis, in effect, self-sealing-immune from any possible refutation. On page 137 he argues: "All that are needed to disprove the claim of Principle II, then, are assertions of fact, opinion, or value reproduced in the mass media of a society which do in fact contradict the necessity or value of social rule." Now, however, this counter-evidence becomes evidence for his theory. Presumably, if the mass media only presented material attacking the social system, this also could be used as evidence of an attempt of the powers that be to present an image of tolerance. ${ }^{11}$ How, given such a view of the world, can his thesis be disproved? Even if there was complete criticism of the government, that could be rationalized as merely allowing protest but not making any substantive changes.

Suppose I argued an opposite conclusion from that advocated by McMurtry: the mass media only publishes stories attacking the B.S.S.F. In response to his examples, I respond, "Aha!; that just proves my point. The mass media only publishes pro B.S.S.F. stories to pretend it promotes diversity. It pretends to be tolerant when it really only tolerates criticisms of the B.S.S.F." Why is this conclusion (the opposite of McMurtry's) any more unreasonable than his conclusion?

For many of the viewpoints which McMurtry argues are not covered in the mass media, the complaint is undermined because the opposite of these viewpoints do not appear in the mass media. While the mass media does not attack religious based justifications for war ( $\# 20$ ), I have not seen such justifications advanced in the mass media. In fact, I cannot think of reading the opposite of any of the thirty "unspeakable" arguments in the mass media. When has the mass media published that industry is harmed by pollution or that military spending hurts industry? These issues are not "unspeakable," they are merely issues that are not addressed at all, in either a manner pro-state or anti-state, because our emphasis is on other issues. One could equally argue that the mass media "censors" pro-social order speech by citing the opposite of the thirty "unspeakable" arguments as being "unspeakable".

A casual reading of right-wing publications such as Human Events or National Review would reveal a number of arguments that would support the B.S.S.F. that are not covered in the mass media. The well documented benefits of $\mathrm{CO}_{2}$ to agriculture or the studies defending acid rain $^{12}$ are rarely mentioned in the mass media. There is very little discussion of the libertarian philosophy. Why did the collapse of statesocialism in the Soviet Union and Eastern Europe come as a surprise to our society? If McMurtry's thesis is true, the impending collapse should have been the topic of every newspaper and television station. Why did the CIA continually report that the USSR had a significantly higher GNP than recent reports suggest is credible? Why did the mass media not report on the millions killed in the Soviet "Harvest of Sorrow" or the existence of Soviet controlled Polish concentration camps after World War II? Where were the stories on the Soviet subsidies of Cuba? ${ }^{13}$ Where were the reports of the genocide of Pol Pot's Khmer Rouge? All of these omissions clearly contradict his "Principle IV"; nor can they be justified as exceptions that prove society's tolerance.

It is also worth noting that criticisms of the B.S.S.F. need not match defenses of the B.S.S.F. one-to-one to satisfy McMurtry's criticisms. As long as it is moderately easy 
to locate attacks on the B.S.S.F., the mass media should pose no barrier to effective critical thinking.

Finally, McMurtry also fails to explain how the system operates to allow minor dissent, but not major dissent. If I want to criticize the government, where do I go to make sure that the quota for dissent has not been filled? Where are the massive arrests for dissenting? How are arguments kept from the mass media?

\section{The Need for Assumptions}

McMurtry's criticism of the mass media also suffers from a misunderstanding of the mass media. There are millions of potential arguments in the world and billions of potential statements that could be deemed worthy of coverage in the mass media. Libraries are filled with articles and books addressing a number of issues; any one of those issues could be deemed worthy of inclusion in the mass media. The mass media (and any critical thinker) must make choices about which arguments should be researched, analyzed, developed, and evaluated, and which arguments should be either assumed or ignored. Edward Jay Epstein suggests:

In the more complex and ambiguous recesses of political life, where the outcome is almost always in doubt or dispute, news reports could not be expected to exhaust, or perhaps even indicate, the truth of the matter. This divergence between news and the truth stemmed not from the inadequacies of newsmen but from exigencies of the news business which limited the time, space, and resources that could be allotted to any single story. ${ }^{14}$

If the mass media attempted to cover every issue, fact, assumption, implicit value, and proposed policy in depth, we would be swamped with facts and we would be unable to absorb all the information. ${ }^{15}$ As a result, we-as teachers, critical thinkers, arguers, logicians, and/or citizens-need to be selective in deciding what arguments we analyze. Similarly, the mass media is forced to make decisions about what is news and what material should be excluded from the mass media. ${ }^{16}$ This process means that the mass media inherently must neglect discussion of many issues. Given the finite space in the mass media, if the mass media included McMurtry's "unspeakables", the result would be that much of what is now in the mass media would be left out, shifting that material into the zone of the "unspeakables."17

The limited number of messages that the mass media can present to the public does not, by itself, negate McMurtry's thesis; if the mass media uses their finite amount of space in a manner that is "subverting of reason" (p. 133), his argument would still be persuasive. In any mass media system, however, there will be arguments that could be included in the mass media but are not; a critic of the system could point to those arguments that were left out and claim that these arguments are "unspeakable" when, in fact, the exclusion of these arguments might be done for rational reasons; excluding these arguments may enable us to focus in more depth on other, more important arguments that otherwise would be crowded out of the system. McMurtry may be correct that the mass media does not cover certain arguments; that does not mean that it should cover those arguments.

In fact, many of the exclusions criticized by McMurtry could be justified because they are low-priority arguments that a rational mass media system would exclude in order to address higher priority arguments. Rather than promoting "unreason", the mass media may be promoting rational argument by focusing our attention on more important issues instead of issues of lower priority. The fact that the lower priority arguments happen to criticize the B.S.S.F. does not mean the mass media system promotes unreason.

To develop a rational system of argument, some criteria must be established to 
determine what arguments we should raise in the mass media and what arguments should be left out. There are a number of possible criteria that could rationally be used to justify the "restrictions" that McMurtry complains about. These rational restrictions could explain why a number of the "impossible statements" which he complains are not covered by the mass media are excluded. This is not a matter of "precluding individuals from communicating." There is nothing to preclude the statements being made in journals, books, public discussion, and so on. Critical thinkers can easily locate copies of Marx in bookstores (probably more easily than they can locate works by Adam Smith). Left-wing publications can find ample financial support. ${ }^{18}$ The question is, however, given a finite amount of time and resources, how should the finite resources of the mass media be allocated? ${ }^{19}$

\section{What Should the Mass Media Report?}

Suppose I had written an identical article to McMurtry's, except that I had changed the examples and included the following "unspeakable" arguments:
A. Anarchy is the best form of government. (or)
B. Tyranny is desirable because liberty and freedom are evil.
C. Genocide would be beneficial.
D. A nuclear war would be good.
E. UFO's exist.
F. Air pollution helps agriculture.
$G$. The earth would be better off if all humans died.
H. Women should have no rights.
I. Minorities are inherently inferior to whites.
J. Slavery is good.
K. Philosophers are the largest source of misery in the world today.
L. The extinction of species is good.
M. Employment is bad.
N. The world is flat.
O. Driving on the left side of the road would reduce the number of tornados in the Northern hemisphere.

Every argument McMurtry advances for why the current mass media subvert reason would apply to a medium that excluded the statements on this list. ${ }^{20}$ This list consists of a number of positions that almost never appear in the mass media. These positions cannot be rejected out of hand since there are individuals who have advanced almost every one of these positions. Yet a system which excludes these arguments from the mass media would not bother me very much (assuming individuals had the freedom to express these arguments in other channels). There could be a number of rational reasons for excluding such discourse from the mass media.

First, the mass media should exclude the false from public discourse. This guideline, of course, is ambiguous, since what is false to some individuals may be true to others. It is always possible that an opinion that we view as being false ends up being true. The decision to exclude some arguments in favor of others inherently risks excluding the truth. Unfortunately, someone or some group has to decide what arguments are more likely to be true than others, and this requires eliminating some arguments because they are not viewed as having a great deal of likelihood of being true. This decision may be made easier if some of these arguments have been made before and resolved. A number of McMurtry's examples might be excluded since the issues raised have been debated before and the conclusions have been determined to be false. While there may be some who disagree with the conclusion of society, it would make much more sense to address those issues that are still being actively debated instead of those issues settled long ago. If significantly new information is discovered, the debate can be reopened; individuals who wish to reopen the controversy can start at the grass roots level or within academia. The mass media would be much better off addressing areas of ongoing controversy than to pursue dead ends. 
To be sure, there are limitations to this perspective. The mass media (or other sources) would make this determination, but there needs to be some manner of separating the good arguments from the bad. The editors of mass media publications act as a testing ground for the effectiveness of the arguments that are advanced. If an editor rejects an idea as being unpersuasive or false, it is quite possible that the public would also reject the argument even if it were printed. My guess would be, for example, that a publication publishing the "unspeakable" arguments would not be read.

McMurtry argues: "Good evidence or reason can be given to support all of these assertions [referring to his "unspeakables"], and none commits an evident error of logic or fact" (p.139). This statement, at best, is overstated. Many of the issues he outlines have been raised and discussed for centuries, and the conclusion our society has reached is that some of these premises are false and/or inconsistent with the evidence. Such "unspeakable" premises as \#1: "Taking more out than you put in as a regular practice-as in money profits--is morally wrong"; \#4: "Unearned wealth should be abolished as a matter of public policy"; \#14: "There is no correlation between people's wealth and their merit"; \#15: "In many cases, social ownership of major industries is sound social policy"; \#17: "A small minority's monopoly ownership of society's means of production is an issue that needs to be carefully examined"; \#19: "Our major social problems are caused by the profit imperative overriding all other values"; \#23: "Socialist revolution has been by and large beneficial for the living standards of most citizens in societies where it has occurred."; \#26: "The business community has excessive political and economic power in our society"; and \#30: "The mass media are essentially a joint-stock company of profit and advertising for major private corporations" would clearly be rejected as inconsistent with the evidence by numerous individuals. For many of the issues, even if there is evidence supporting McMurtry's "unspeakables" (something that has been greatly undermined by the events in the last couple of years), the evidence is often overwhelmed by counter-arguments.

Suppose, however, that McMurtry is correct that all criticisms of our form of government have been suppressed. There is a second reason why such discussion could be relegated to a minor importance in the marketplace of ideas: some "unspeakables" concern issues that are unlikely to be changed. To my knowledge, there has been no great demand to significantly alter our form of government. It is highly unlikely that, even if every argument McMurtry advances were made public, our government would undergo dramatic change. Given this fact, there seems to be no great need to devote energy debating issues that are unlikely to ever be altered. Instead, it would make sense to focus on eliminating the major problems brought on by capitalism, changing the system gradually rather than dramatically overturning it. ${ }^{21}$

Third, some material can be excluded from the mass media because it is not appropriate for the mass media. McMurtry's indictment is directed at the mass media. I do not think he could argue that the "unspeakable" arguments cannot be located in any source in the library. In fact, my guess is that any student with a reasonable knowledge of the library can locate any of the "unspeakable" arguments he cites in less than fifteen minutes in any decent library. The question is, why must these arguments be located in the mass media, as opposed to other locations?

It does seem reasonable that, given the complexity of argument in our society, that some division of responsibility is needed in order to examine arguments in depth. One would not expect to be able to reach a conclusion about any major public policy issue without researching the issue in the library. It would make sense to permit some issues to be discussed openly in the 
mass media, while other issues would be discussed in specialized journals, open to anyone who is interested in them. If the public is interested in the issues McMurtry raises, they can read Zeta, the World Marxist Review, or the Socialist Review. Why must they appear in the New York Times?

This argument has another implication. The reason a medium is part of the mass media is because people choose to buy a publication. Publications such as Nation, the Progressive, and In These Times can readily be found on any major newsstand in the United States. All of these publications contain many of the "unspeakable" statements. The reason McMurtry would exclude these publications from the "mass media" is probably that they are not widely read, but that is a choice made by readers. ${ }^{22}$ If a mass media publication became more like the Nation, it would probably quickly lose circulation and exit from the mass media. At best, his argument may be, don't read the New York Times; read Progressive (or read both).

A number of arguments would best be developed in more specialized publications. For example, the mass media does not discuss such topics as the forward based maritime strategy, our military bases in Diego Garcia, anti-satellite warfare, and a variety of other topics in depth, yet these significant subjects are treated in depth in a number of other sources reflecting a variety of perspectives. The perspectives are available to anybody that wants the information. A good critical thinker would presumably look up these sources before reaching a conclusion about the topic. If McMurtry's argument is that a good critical thinker should be able to decide rationally on major issues of contemporary policy without going to the library, his view is naive. If a critical thinker does go to the library, who cares if one source of information does not present all perspectives as long as the overall structure presents diverse viewpoints? Furthermore, the evidence is quite clear that the perspective he advocates is strongly entrenched in colleges and universities; why the mass media need to provide this perspective is unclear. ${ }^{23}$

Fourth, arguments may be left out of the mass media if they are irrelevant to ongoing debate or are trivial. Whether or not industry profits from military spending $(\$ 9)$, for example, is irrelevant to whether or not we should spend money on the military.

Fifth, arguments covered in the mass media should be timely. What companies did in World War II (\#3) or in the distant past (\#12) cannot be changed; what can be changed and what we should be arguing about is what actions we should be taking in the future. While the past is certainly relevant to these decisions, the purpose of mass media is not to replace history books; rather it is to focus on ongoing issues of controversy. History should be mentioned in the mass media only if it is more relevant to understanding the choices facing us than other information.

It is not my argument that the current mass media system is perfect. There are a number of topics not covered by the mass media that are important. I do suggest, however, that the fact that material is not included in the mass media does not make the system subverting of reason. Most of the "unspeakable" arguments mentioned by McMurtry would be excluded under a totally rational system of mass media communication.

\section{Conclusion}

McMurtry's view of the mass media is inaccurate; the mass media covers many stories attacking our basic social structure. In addition, his view of the role of the mass media is simplistic. The purpose of mass media is complex, and includes both entertainment and news gathering purposes. To expect mass media to convey all the necessary information required for making critical decisions is naive. 
We cannot intelligently understand and evaluate all potential arguments in the world around us. We need to make choices about what arguments to evaluate and what arguments to ignore. In so doing, there are some premises that must go unquestioned and some assumptions that must be made. This decision is both inevitable and imperfect; mistakes can and will be made. There are guidelines that can assist in the making of this decision, such as the timeliness of the issue, the likelihood that the assumption will be changed, the probable truth of the premise, and so on.
The bias in the mass media system can and should be compensated for by extensively researching any subject. No rational individual should rely on the mass media in forming a judgement; this argument by itself makes McMurtry's attack on the mass media irrelevant. If the mass media was dominated by Human Events (or the Progressive) it would present a slanted view of the world, but this would not be harmful since other sources of information exist. In reality, however, our mass media does not approach the degree of bias cited by McMurtry, given the type of decisions facing our citizens.

\section{Notes}

*The author would like to express his gratitude to J. Anthony Blair for his extensive comments and suggestions on earlier drafts of this essay.

I John McMurtry, "The Unspeakable: Understanding the System of Fallacy in the Media," Informal Logic, 10 (Fall 1988), pp. 133-150. Subsequent references to this article will simply list the page in the text.

2 While McMurtry argues that the mass media does not publicize arguments that contradict the value of the B.S.S.F., many of his examples (\#8: "Over $70 \%$ of eligible U.S. and British voters did not vote for Reagan or Thatcher "landslides."; \#12 "The history of Western civilization is largely a history of genocide against non-white peoples and cultures."; \#28; "The President and his leading advisors are provable war criminals"; and numbers 7,13 , 20 , and 21 are at best tangentially related to the value of the B.S.S.F.

3. In the same issue, there is a more extended article raising some of these issues (John Dolan, "Consent as a Commodity," [review of Herman and Chomsky, Manufacturing Consent] Informal Logic, 10 (Fall 1988), pp. 177-194), but as McMurtry notes (p. 147, note 3 ) the book reviewed focuses on limited aspects of the mass media. In addition, several of the issues raised by the book are not relevant to the arguments made by McMurtry (e.g., that the mass media is concentrated does not prove content bias). For a different view of the media see William A. Rusher, The Coming Battle for the Media (New York: William Morrow, 1988); Marlin Maddoux, Free Speech or Propaganda: How the Media Distorts the Truth (Nashville, TN: Thomas Nelson, 1990), or any of the publications by Accuracy in Media.

4 The democratic nature of our society would promote the discussion of attacks on capitalism and the promotion of minority rights, which contradicts several other versions of the B.S.S.F.

5 "Left Not Hanging," The Progressive, April 1990. p. 9.

6 See Jude Wanniski, editor, The 1989 Media Guide: A Critical Review of the Print Media (Morristown, NJ: Polyconomics, 1989), pp. 14-17.

7 See the report of the Center for Media and Public Affairs study on the press coverage, summarized in Insight, May 27, 1991, p. 12.

8 See Jude Wanniski, editor, The 1991 Media Guide: A Critical Review of the Print Media (Morristown, NJ: Polyconomics, 1991), pp. 30-33.

9 "The Pope Challenges Capitalism," World Press Review, July 1991, pp. 49-50.

10 See also the article by Robert Reich in the January 20, 1991 issue of the New York Times Magazine, cited in Zeta, June, 1991, p. 11. which argues the top fifth of the country is "quietly seceding from the rest of the nation." 
11 McMurtry's argument is similar to that made by Herbert Marcuse and others; see Robert Paul Wolff, Barrington Moore, Jr., and Herbert Marcuse, A Critique of Pure Tolerance (Boston: Beacon Press, 1965). Marcuse suggests that society tolerates minor dissent in order to defuse broader criticism of capitalism.

12 For example, the National Acid Precipitation Assessment Project has been overlooked by the media (see "The Week," National Review, January 28, 1991, p. 12).

13 Incidently, his "unspeakable" \#22 (The Soviet Union pays significantly more than the worldprice for imports from the countries of East Europe, and charges less for its exports) could be interpreted as proving that socialism in Eastern Europe survived only because of subsidies from the Soviet Union.

14 Edward Jay Epstein, Between Fact and Fiction (New York: Random House), 1975, p. 4.

15 See Doris A. Graber, Processing the News: How People Tame the Information Tide, second edition (New York: Longman, 1988).

16 See Elie Abel, editor, What's News: The Media in American Society (San Francisco: Institute for Contemporary Studies, 1981); and Herbert J. Gans, Deciding What's News: A Study of CBS Evening News, NBC Nightly News, Newsweek and Time (New York: Vintage Books, 1980).

17 See Miami Herald Publishing Co. v. Tormillo, 418 U.S. 241 (1974). There are a number of potential roles for the mass media in a society. See Fred S. Siebert, Theodore Peterson and Wilbur Schramm. Four Theories of the Press (Urbana: University of Illinois Press, 1956).

18 See "The Lure of the Left," Lingua Franca, June, 1991, p. 14.

19 See Walter Ulrich, "Determining What Arguments are Critical," in Dimensions of Argument: Proceedings of the Second Summer Conference on Argumentation, edited by
George Ziegelmueller and Jack Rhodes, Annandale, VA: Speech Communication Association, October 15, 1981, pp.544-553. This issue is also raised in the debates over the faimess doctrine of the Federal Communications Commission. See Federal Communications Commission, "Fairness Report," 48 F.C.C.2d, 30 R.R.2d 1261 (1974).

20 The fact that these statements do not attack the B.S.S.F does not deny that the mass media system could be charged with promoting "unreason" by ignoring arguments. McMurtry gives no reason why attacks on the B.S.S.F. should be given higher priority than any other statement the mass media may report.

21 There is an interesting response to this argument sometimes made by opponents of capitalism: that incremental changes merely prop up the system. However, if all the evils of capitalism can be eliminated with incremental changes, this charge is irrelevant since all problems would be solved by a modified capitalism. The anti-capitalist ends up attacking the label, not the concept.

22 His inclusion of school textbooks in the mass media (footnote 2) overlooks the considerable controversy over the "Politically Correct" movement in America which does systematically attack the B.S.S.F.

23 See Paul Hollander, "Communism's Collapse Won't Phase the Marxists in Academe," Chronicle of Higher Education, May 23, 1990, p. A44; Paul Hollaner, Political Pilgrims (New York: University Press of America, 1990); and Roger Kimball, Tenured Radicals: How Politics Has Corrupted Our Higher Education (New York: Harper and Row, 1990).

WALTER ULRICH

DEPARTMENT OF COMMUNICATION

AND THEATRE ARTS

UNIVERSITY OF NORTHERN IOWA

CEDAR FALLS, IOWA 50614-0357 